\title{
TEKNIK YOGA SEBAGAI INTERVENSI DALAM MELAKUKAN ANGER MANAGEMENT PADA WANITA DEWASA AWAL
}

\section{YOGA TECHNIQUES EVIDENCE-BASED PROCEDURES THAT REDUCE ANGER AND PROMOTE WELL-BEING}

\author{
Anissa Lestari Kadiyono \\ Febbyros Anmarlina \\ Fakultas Psikologi Universitas Padjadjaran Bandung \\ Email: anissa.lestari@unpad.ac.id
}

\begin{abstract}
The purpose of this study is to examine the effect of yoga technique to improve anger management. The design of this study is a quasi-experimental method. The study compared two groups: group with yoga (n $=60)$ and no yoga $(n=60)$. Respondents aged between 20-40 years $(M=46.15, S D=7.017)$. Data processing was performed with the Mann-Whitney $U$ test on two groups of test criteria reject $\mathrm{HO}$ if the $p$ value $<0.05$. The results showed a p-value of 0.000, which means there was a difference anger management in women with yoga than those women without yoga. This research showed that yoga techniques becomes alternative way to manage angry emotions. Yoga helped anger management, calm minds, reduce stress, provide improved awareness and alertness of the body.
\end{abstract}

Keyword : anger management, young adult, yoga techniques

\begin{abstract}
ABSTRAK
Penelitian ini bermaksud mengetahui pengaruh teknik Yoga terhadap kemampuan manajemen marah. Rancangan penelitian ini adalah metode kuasi-eksperimen. Penelitian ini membandingkan dua kelompok, yaitu kelompok yang mengikuti yoga $(n=60)$ dan kelompok tidak mengikuti yoga $(n=60)$. Responden berada pada kategori dewasa awal yang berusia 20-40 tahun $(M=46,15, S D=7,017)$. Pengolahan data dilakukan dengan uji Mann-Whitney $U$ pada dua kelompok dengan kriteria uji tolak $\mathrm{H}_{0}$ bila p-value < $<, 05$. Hasil penelitian menunjukkan p-value 0,000 yang berarti terdapat perbedaan anger management pada wanita yang mengikuti yoga dibandingkan yang tidak mengikuti yoga. Hal ini menunjukkan bahwa teknik yoga menjadi salah satu cara dalam mengelola emosi marah seseorang. Yoga membantu dalam mengatasi rasa marah, menenangkan pikiran, mengurangi stres, memberikan peningkatan kesadaran dan kesiagaan tubuh.
\end{abstract}

Kata Kunci: manajemen marah, dewasa awal, teknik yoga

Menurut Santrock (1999), masa dewasa awal termasuk masa transisi, baik transisi secara fisik (physically trantition), transisi secara intelektual (cognitive trantition), serta transisi secara peran sosial (social role trantition). Banyak peran dan 
tanggung jawab yang harus diemban oleh dewasa awal, terlebih pada wanita. Wanita yang memasuki tahap dewasa awal mengalami beberapa peran yang dapat mengakibatkan tekanan, baik itu berupa melanjutkan sekolah ke perguruan tinggi, memiliki pekerjaan, menikah, berkeluarga, mengasuh anak, ataupun mandiri secara finansial untuk dapat memenuhi berbagai kebutuhan hidupnya.

Berdasarkan data dari Rumah Sakit Hasan Sadikin Bandung pada tahun 2013 setidaknya terdapat 600.000 orang yang mengalami stres di Bandung. Tingginya permasalahan hidup yang dialami masyarakat perkotaan termasuk di kota Bandung berakibat pada banyaknya masyarakat yang stres, menderita kesehatan jiwa dan cenderung menurunkan tingkat kebahagiaannya.

Setiap wanita memiliki cara yang berbeda dalam menghadapi masalah yang dialami. Ada yang memilih untuk menyelesaikan sendiri dengan merenungkan masalah yang sedang dihadapi dan pada akhirnya tidak menjalankan tugastugas yang menjadi tanggung jawabnya. Permasalahan masa dewasa awal pada wanita disebabkan ketidakmampuan untuk menyelesaikan masalah yang dihadapi dan ketidaksesuaian tugas perkembangan yang dilaksanakan yang kemu- dian menimbulkan ketegangan emosi dan akhirnya menjadi pemicu timbulnya stres. Menurut Scheiman (Potegal, Stemmler, \& Spielberger, 2010), wanita yang mengalami stres dapat memicu perasaan marah. Marah yang dialami oleh individu merupakan reaksi emosional yang ditimbulkan dikarenakan terdapat situasi yang mengancam, terdapat agresi, pengekangan diri, atau serangan lisan kekecewaan, maupun frustrasi. Pengungkapan kemarahan dengan langsung dan konstruktif akan melegakan individu dan membantu orang lain untuk mengerti perasaan yang sebenarnya. Namun demikian, perlu dipertimbangkan beberapa faktor sehingga kemarahan tersebut tidak menimbulkan kerugian pada kedua belah pihak. Kemarahan yang ditekan atau disembunyikan akan mempersulit sendiri dan mengganggu hubungan interpersonal. Dalam konsep marah (Beck, Rawlins, \& Williams, dalam Kelliat, 1993) marah dipicu oleh adanya suatu ancaman atau kebutuhan yang tidak terpenuhi, kadar stres, perasaan cemas yang dialami individu saat itu yang akhirnya menimbulkan kemarahan. Ketika individu dapat memutuskan rangkaian stres bahkan hingga rasa cemas, maka kemarahan pun tidak akan terjadi (Beck, Rawlins, \& Williams, dalam Kelliat, 1993). 
Marah merupakan emosi negatif yang paling sulit dikendalikan (Goleman, 1997). Marah memiliki dua sisi yakni sisi positif dan negatif. Memiliki makna positif jika marah diekspresikan dengan cara yang tepat sehingga dapat membantu individu dalam mengekspresikan berbagai perasaan dengan cara yang dapat diterima lingkungan, membantu menyelesaikan masalah, dan mampu memotivasi dalam mencapai tujuan yang positif. Memiliki makna negatif, jika marah diekspresikan dalam cara yang tidak tepat seperti bertindak agresi baik secara verbal maupun non verbal yang dapat mengganggu hubungan interpersonal. Pada saat merasa marah, individu dapat melakukan tindakan yang merugikan dan merusak diri sendiri, orang lain, maupun lingkungan fisik di sekitarnya (Bhave \& Saini, 2009).

Kemarahan adalah suatu emosi yang secara fisik mengakibatkan peningkatan denyut jantung, tekanan darah, serta tingkat adrenalin dan noradrenalin. Kemarahan dapat berdampak negatif pada kualitas hubungan dan membuat orang lain tidak ingin bernegosiasi di masa depan (Allred dkk, 1997). Hal positif dari kemarahan adalah jika intensitas yang rendah, diekspresikan secara verbal dibandingkan fisik, kemarahan tersebut akan sesuai dengan norma (Denson \& Fabiansson, 2010).

Kemampuan dalam mengelola kemarahan atau anger management merupakan hal yang penting dilakukan dalam kehidupan manusia karena manusia dituntut untuk mampu mengekspresikan kemarahan yang mereka miliki dengan cara yang dapat diterima oleh lingkungan, dan tidak menyakiti diri sendiri ataupun orang lain. Anger management membantu individu untuk mengurangi rasa marah dan mengatasi dampak psikologis akibat marah. Terdapat beberapa teknik anger management yang dapat digunakan dalam membantu wanita mengelola kemarahannya di antaranya relaksasi, cognitive restructuring/ mengubah cara berpikir, problem solving/penyelesaian masalah, komunikasi yang lebih baik, dan humor (Deffenbacher, dalam American Psychological Association, 2011).

Manifestasi rasa marah dalam Stuart and Sundeen (1991), dapat dilihat dalam bagan sebagai berikut : 
Tabel 1. Manifestasi rasa marah

\begin{tabular}{|c|c|c|c|c|c|}
\hline & $\begin{array}{l}\text { MotorAgitation } \\
\text { (gejalamotorik) }\end{array}$ & & $\begin{array}{l}\text { Verbalizations } \\
\text { (gejala verbal) }\end{array}$ & $\begin{array}{c}\text { Affect } \\
\text { (gejala afek) }\end{array}$ & $\begin{array}{c}\text { Level of } \\
\text { Consciousness } \\
\text { (tingkat kesadaran) }\end{array}$ \\
\hline a. & $\begin{array}{l}\text { Pacing (memaksa/ } \\
\text { mengontrol } \\
\text { kecepatan dalam } \\
\text { pelaksanaan suatu } \\
\text { aktivitas) }\end{array}$ & a. & $\begin{array}{l}\text { Ancaman secara } \\
\text { verbal terhadap } \\
\text { objek nyata atau } \\
\text { fantasi }\end{array}$ & a. Anger (marah) & $\begin{array}{ll}\text { a. } & \text { Confusion } \\
\text { (kebingungan / } \\
\text { kekacauan) }\end{array}$ \\
\hline b. & $\begin{array}{l}\text { Inability to sit still } \\
\text { (ketidakmampu an } \\
\text { untuk duduk diam) }\end{array}$ & b. & $\begin{array}{l}\text { Tuntutan akan } \\
\text { perhatian yang } \\
\text { kacau/ terganggu }\end{array}$ & $\begin{array}{ll}\text { b. } & \text { Hostility } \\
& \text { (permusuhan) }\end{array}$ & $\begin{array}{l}\text { b. Perubahan status } \\
\text { mental yang tiba- } \\
\text { tiba }\end{array}$ \\
\hline C. & $\begin{array}{l}\text { Mengepal / } \\
\text { memukul-mukul }\end{array}$ & C. & $\begin{array}{l}\text { Berbicara dengan } \\
\text { penekanan/ keras }\end{array}$ & $\begin{array}{ll}\text { c. } & \text { Kecemasan } \\
& \text { yang ekstrim }\end{array}$ & c. Disorientasi \\
\hline d. & Rahangterkatup & d. & $\begin{array}{l}\text { Fakta dari } \\
\text { keadaan delusi } \\
\text { dan paranoid }\end{array}$ & $\begin{array}{ll}\text { d. } & \text { Irritability } \\
& \text { (mudah } \\
& \text { tersinggung) }\end{array}$ & $\begin{array}{ll}\text { d. } & \text { Memory impair- } \\
\text { ment (kerusakan } \\
\text { ingatan) }\end{array}$ \\
\hline e. & $\begin{array}{l}\text { Peningkatan } \\
\text { pernafasan }\end{array}$ & & & $\begin{array}{l}\text { e. } \begin{array}{l}\text { Euphoria yang } \\
\text { berlebihan }\end{array} \\
\text { a }\end{array}$ & $\begin{array}{ll}\text { e. } & \text { Tidak mampu } \\
& \text { dialihkan }\end{array}$ \\
\hline f. & $\begin{array}{l}\text { Catatonia (tiba-tiba } \\
\text { aktivitas motorik } \\
\text { terhenti) }\end{array}$ & & & $\begin{array}{ll}\text { f. } & \text { Affect lability } \\
& \text { (efek yang } \\
& \text { labil) }\end{array}$ & \\
\hline
\end{tabular}

Berdasarkan frekuensi, efek, dan kondisinya yang sangat dekat dengan kehidupan manusia, maka sangat penting untuk dapat mengelola emosi marah. Relaksasi merupakan salah satu cara dalam mengelola emosi marah. Yoga merupakan sistem kesehatan menyeluruh (holistik) yang terbentuk dari kebudayaan India sejak 3.000 SM yang lalu. Melalui yoga seseorang akan lebih baik mengenal tubuhnya, pikirannya, dan jiwanya. Yoga merupakan kombinasi unik antara gerakan yang bermanfaat untuk meningkatkan kesehatan fisik dan cara bernapas serta meditasi yang dapat memberikan ketenangan pikiran. Berbagai macam gerakan yang disertai cara bernapas yang benar dipercaya dapat meningkatkan kekuatan dan kelenturan, meredakan ketegangan, serta memberikan energi baru pada tubuh (Shindu, 2013). Menurut Jain (2011), dalam yoga dilakukan teknik pernapasan, relaksasi, meditasi, dan latihan peregangan. Relaksasi yang ada dalam yoga dilakukan secara teratur bersamaan dengan dilakukannya teknik bernapas yang baik, latihan peregangan, dan meditasi (Jain, 2011). Yoga meng- 
ajarkan cara-cara berkonsentrasi yang dapat membantu menenangkan pikiran dan mengurangi stres dan kecemasan. Saat berkonsentrasi masalah sehari-hari baik besar maupun kecil, akan mencair sehingga akan terbebas dari tekanan stres. Yoga dan kemarahan merupakan dua hal yang berlawanan. Kemarahan memengaruhi proses fisiologis yang terjadi dalam diri individu, antara lain gejala marah yang paling umum meliputi ketegangan otot, kegelisahan umum, meningkatnya detak jantung serta wajah yang terasa panas (Shields, dalam Jain, 2011). Emosi marah memiliki efek baik secara negatif maupun positif. Jika individu tidak menahan perasaan marah dan menunjukkannya dalam cara yang baik, maka akan dapat memberikan beberapa efek positif. Beberapa efek positif di antaranya memotivasi individu untuk lebih percaya diri dan optimis, mengurangi stres dan kegelisahan, serta memberikan efek positif dalam hubungan interpersonal. Jika dilihat dari sudut pandang yang berbeda, kemarahan dapat memberikan efek positif yang baik bagi diri seseorang. Kemarahan juga menandakan bahwa ada sesuatu yang salah dalam situasi yang dihadapi oleh seseorang, mungkin kemarahan jugalah yang menyebabkan mengapa individu berusaha mencari obat di balik suatu penyakit, dan mengapa seseorang meninggalkan hubungan yang buruk. Kemarahan dapat memberikan efek positif hanya jika individu menunjukkannya dalam cara yang benar. Bukan dalam cara yang dikenal secara umum dengan 'meledak-ledak' dan benar-benar negatif. Efek negatif dari marah, di antaranya kemarahan dapat menyebabkan stres, tekanan darah tinggi, rentan terhadap peradangan dan nyeri otot, cepat letih, sulit tidur, melemahkan kekebalan tubuh, menyebabkan isolasi sosial, detak jantung lebih cepat, meningkatkan hormon stres, penyakit stroke, sakit kepala, masalah pernapasan, rasa cemas, depresi, gangguan pencernaan, dan serangan jantung.

Kemarahan merupakan sebuah reaksi yang tidak baik secara emosional atau perilaku. Secara umum, kemarahan berisikan tiga komponen, yaitu pikiran (pemikiran negatif), perasaan (kekecewaan, frustrasi, emosi) dan tindakan (berteriak, kekerasan fisik). Hal ini terlihat tidak baik atau negatif dan sering tidak diterima di masyarakat umum. Salah satu penyebabnya adalah karena banyaknya individu yang menunjukkan kemarahan mereka dalam cara yang salah dan negatif. Hal ini menjadi penyebab mengapa banyak individu yang berusaha menekan atau menahan kemarahannya. 
Pada akhirnya akan keluar dalam bentuk kemarahan besar. Menahan kemarahan hanya akan memperburuk pengalaman dan rasa sakit di belakangnya, bahkan pada akhirnya akan mengarah pada kegelisahan dan depresi. Sedangkan yoga membuat perubahan perasaan tegang ke perasaan tenang dengan memengaruhi tekanan darah, kecepatan jantung, kecepatan pernapasan, dan proses-proses di dalam tubuh serta cara-cara individu berbuat atau merespon secara lahiriah. Yoga berperan aktif dalam meredakan kegelisahan dan mengendalikan gejalagejala stres. Yoga mengajarkan bahwa kondisi alami manusia adalah dalam keadaan tenang. Semakin dalam napas akan memengaruhi detak jantung menjadi lebih perlahan dan memberikan rasa nyaman dan tentram. Selain itu, napas yang dalam juga akan menghantarkan lebih banyak oksigen ke otak yang akan memberikan rasa tenang pada pikiran. Relaksasi bermanfaat menurunkan kadar adrenalin, memperdalam napas, menenangkan jantung, menurunkan tekanan darah, meredakan ketegangan otot tubuh, dan mengaktifkan kembali sistem tubuh agar lebih kuat saat menghadapi penyakit (Shindu, 2013).

Yoga menurunkan kecepatan denyut jantung, menurunkan tekanan darah, membantu kelancaran sirkulasi darah dalam tubuh, memperdalam napas, dan meningkatkan konsentrasi. Hipotalamus, menurut Copstead dan Banasik (Shindu, 2013), dapat dimanipulasi agar secara minimal terhadap stressor, dengan cara menghiraukan stressor meskipun dengan konsekuensi tingkat atau level stressor tetap dipertahankan oleh individu. Latihan relaksasi dan konsentrasi dalam yoga merupakan sesi latihan yang menggunakan teknik pemusatan pikiran untuk memperkuat sikap positif dalam upaya menurunkan tingkat stres. Menurut Claire (Shindu, 2013), relaksasi yang mendalam dapat melepaskan ketegangan fisik, mental, emosi, dan spiritual. Relaksasi akan mengembalikan keadaan tubuh menjadi stabil apabila ada yang kelebihan oksigen di tempat-tempat tertentu. Dengan melakukan relaksasi maka tubuh dan pikiran menjadi tenang karena oksigen yang berada dalam tubuh seimbang sehingga dapat memperlancar peredaran darah.

Berdasarkan paparan di atas, peneliti tertarik untuk melakukan penelitian empiris dan sistematis untuk dapat mengetahui perbedaan anger management pada wanita dewasa awal yang mengikuti yoga. 


\section{METODE PENELITIAN}

\section{Desain Penelitian}

Penelitian ini menggunakan metode kuasi-eksperimen. Desain yang digunakan adalah posttest control group. Karenanya, dalam penelitian ini terdapat dua kelompok, yaitu kelompok eksperimen dan kelompok kontrol. Pada kelompok kontrol, tidak dilakukan apa pun sebagai intervensi atas kondisi emosi marah yang dimiliki oleh responden. Sedangkan pada kelompok eksperimen, dilakukan yoga. Latihan yoga dilakukan dalam waktu 1,5 jam di mana seminggu dilakukan 2 kali kegiatan.

Pengukuran dilakukan setelah kelompok eksperimen telah melakukan yoga pada pertemuan ke 8 atau setelah 4 minggu melakukan yoga. Hal ini dimaksudkan agar peserta dapat memahami perbedaan yang dialami setelah melakukan yoga dan dapat mengevaluasi dirinya baik dari segi fisik, psikis, dan perilaku setelah melakukan beberapa kali yoga.

\section{Subjek Penelitian}

Subjek penelitian wanita pada usia dewasa awal, yaitu berusia antara 20-40 tahun. $M=46.15, S D=7.017$. Subyek dibagi ke dalam 2 kelompok, yaitu kelompok eksperimen dan kontrol.
Kelompok eksperimen adalah kelompok yang diintervensi menggunakan latihan yoga, sedangkan kelompok kontrol adalah kelompok yang tidak melakukan yoga. Jumlah masing-masing kelompok sejumlah 60 orang sehingga seluruh sampel berjumlah 120 orang. Pemilihan sampel penelitian didasarkan pada asesmen awal, di mana wanita dewasa awal diminta melakukan asesmen diri untuk mengukur apakah terdapat kadar emosi marah yang berada pada level moderat. Hal ini ditandai dengan merasa sering mengalami masalah dalam hidup, sering mengalami sakit kepala, seringkali marah-marah tanpa sebab, merasa sering cepat marah, dan merasa memiliki banyak beban pekerjaan baik di kantor maupun di rumah. Hal ini termanifestasi dari segi fisik, psikis, dan perilaku. Yang memiliki kadar emosi marah moderat dan tinggi kemudian dipilih sebagai responden dan dibagi menjadi dua kelompok sampel penelitian, yaitu kelompok eksperimen dan kelompok kontrol. Penelitian ini dilakukan di kota Bandung, di mana intervensi berupa yoga dilakukan di 4 Pusat Yoga di kota Bandung.

\section{Metode Pengumpulan Data}

Pengumpulan data melalui asemen kondisi emosi marah yang dimiliki oleh responden melalui mekanismen anger 
management yang dilakukan baik pada kelompok kontrol maupun pada kelompok eksperimen. Menurut Goleman (1997), anger management adalah suatu teknik atau tindakan untuk mengatur pikiran, perasaan, nafsu amarah dengan cara yang tepat dan positif serta dapat diterima secara sosial, sehingga dapat mencegah sesuatu yang buruk atau merugikan diri sendiri dan orang lain. Tujuan dari anger management adalah untuk mengurangi rasa marah dan dampak psikologis akibat marah. Anger Management akan mengacu pada kemampuan untuk mengenali emosi marah diri sendiri, mengendalikan emosi marah, meredakan emosi marah, mengenali emosi marah orang lain, dan mengungkapkan amarah secara asertif.

Anger Management mencakup hal sebagai berikut. Pertama: Emotional Awareness. Hal ini mencakup kemampuan dalam mengenali emosi marah dalam diri dan mengenali faktor-faktor apa yang menjadi penyebabnya. Indikator penilaian aspek ini adalah (a) Anger Awareness, yaitu kemampuan mengenali hal-hal yang menjadi pemicu munculnya kemarahan. Contoh aitem: Ketika harapan saya tidak terwujud, saya akan marah pada diri sendiri karena saya merasa gagal. (b) Accurate Self-Assessment, yaitu kemampuan mengenali kondisi fisik dan psikis yang menjadi penyebab marah. Contoh aitem: Saat kondisi tubuh sangat lelah, saya menjadi rentan untuk menjadi mudah marah.

Kedua: Anger Regulation. Hal ini mencakup kemampuan mengendalikan emosi marah. Indikator penilaian aspek ini adalah (a) Self Control, yaitu kemampuan mengelola emosi marah dan impuls yang mengganggu. Contoh aitem: Saya dapat bersikap tenang dalam menghadapi orang yang marah terhadap saya. (b) Adaptability, yaitu kemampuan bersikap fleksibel dalam menghadapi perubahan pada kondisi yang membuat marah dirinya. Contoh aitem: Saya melampiaskan rasa marah saya pada orang lain, daripada harus menghadapi langsung orang yang membuat saya marah.

Ketiga: Calming techniques. Hal ini mencakup kemampuan meredakan emosi marah. Indikator penilaian aspek ini adalah (a) Commitment, yaitu kemampuan menyelaraskan tujuan-tujuan diri pada kelompok untuk menjaga batas kemarahan sehingga tidak merugikan diri sendiri maupun orang lain. Contoh aitem: Saya dapat memendam rasa marah agar keharmonisan lingkungan tetap terjaga. (b) Innitiative, yaitu kesiapan untuk bertindak dalam setiap kesempatan yang ada dengan melakukan teknik mengendalikan emosi marah. 
Contoh aitem: Ketika saya marah, saya akan diam dan pergi menyendiri untuk menenangkan pikiran dan perasaan saya.

Keempat: Evaluating Strategies. Hal ini mencakup kemampuan berempati dan kemampuan mengungkapkan rasa marah secara asertif. Indikator penilaian aspek ini adalah (a) Understanding Others, yaitu kemampuan memahami perspektif orang lain dan ekspresi yang berbeda-beda. Contoh aitem: Saya tetap memperhatikan perasaan orang lain, meskipun sedang marah. (b) Leveraging Diversity, yaitu kemampuan menerima perbedaan dan memahami keberagaman emosi orang lain. Contoh aitem: Saya tahu bahwa ekspresi marah orang lain itu berbeda-beda. (c) Communication, yaitu kemampuan mengkomunikasikan pendapat dan mendengarkan secara aktif. Contoh aitem: Saya tidak mau mendengarkan saran apapun dari orang lain ketika saya sedang marah.

\section{Teknik Intervensi}

Intervensi terhadap anger management dilakukan teknik yoga. Yoga adalah suatu mekanisme penyatuan dari tubuh (body), pikiran (mind) dan jiwa (soul). Yoga bermanfaat untuk menenangkan pikiran, mengurangi stres, memberikan peningkatan kesadaran dan kesiagaan tubuh. Di dalam yoga, terdapat gerakan- gerakan yang harus diikuti, ditambah dengan pengaturan nafas, dan meditasi. Hal ini merupakan teknik dalam melakukan relaksasi. Relaksasi merupakan kebebasan mental dan fisik dari ketegangan dan stres, di mana teknik relaksasi memberikan individu kontrol diri ketika terjadi rasa tidak nyaman atau nyeri, stres fisik dan emosi pada nyeri (Potter \& Perry, 2006).

Rasa marah, stres, atau perasaan cemas akan mencetuskan beberapa sensasi dan perubahan fisik, meliputi peningkatan aliran darah menuju otot, ketegangan otot, mempercepat atau memperlambat pernapasan, dan meningkatkan denyut jantung. Jika hal ini berlangsung terus menerus, maka respon psikofisiologikal yang berulang dapat membahayakan kondisi tubuh. Oleh karenanya, gerakan fisiologis berupa latihan relaksasi akan membalikkan efek stres yang melibatkan bagian parasimpatik dari sistem saraf pusat. Relaksasi akan menghambat peningkatan saraf simpatik, sehingga hormon penyebab disregulasi tubuh dapat dikurangi jumlahnya. Sistem saraf parasimpatik yang memiliki fungsi kerja yang berlawanan dengan saraf simpatik akan memperlambat atau memperlemah kerja alat-alat internal tubuh. Akibatnya terjadi penurunan detak jantung, irama napas, 
tekanan darah, ketegangan otot, tingkat metabolisme, dan produksi hormon penyebab stres. Seiring dengan penurunan tingkat hormon penyebab stres, maka seluruh badan mulai berfungsi pada tingkat lebih sehat dengan lebih banyak energi untuk penyembuhan (healing), penguatan (restoration), dan peremajaan (rejuvenation) (Potter \& Perry, 2006).

Meditasi dalam yoga dimaksudkan untuk menghilangkan pikiran-pikiran yang ada dengan memfokuskan satu titik dan mengkonsentrasikannya dengan nafas, berupaya menenangkan pikiran, mendamaikan pikiran, serta menanamkan pemahaman dan penerimaan diri yang lebih besar. Meditasi akan membantu untuk menenangkan dan mengurangi kemarahan (Bhave \& Saini, 2009), serta mengurangi stres dan mengatasi kecemasan, ketakutan, kekhawatiran, kemarahan, emosi negatif lainnya, meningkatkan pengendalian emosi, membantu menenangkan pikiran (Rawls, 2010).

Bernafas adalah suatu tindakan yang otomatis tanpa harus diperintah untuk melakukannya, tetapi jika individu bernafas dengan cepat dan dangkal akan mengurangi jumlah oksigen yang tersedia dan otak akan bereaksi terhadap hal ini dengan panik. Bagian dari proses panik adalah peningkatan denyut jantung dan peningkatan tekanan darah. Dengan mengatur nafas menjadi lebih pelan dan dalam akan membuat peregangan pada otot-otot tubuh. Hal ini menyebabkan tubuh dan pikiran menjadi lebih relaks, nyaman dan tenang yang membuat penurunan pada tekanan darah. Menurut Jain (2011), teknik bernafas pada yoga berfungsi untuk menenangkan pikiran dan tubuh yang membuat detak jantung lebih tenang sehingga tekanan darah dan produksi hormon adrenalin menurun.

Latihan peregangan secara teratur dapat menguatkan otot jantung yang mengakibatkan jantung dapat memompa lebih banyak darah dengan usaha yang minimal sehingga kerja jantung menjadi lebih ringan. Latihan peregangan juga dapat meningkatkan metabolisme lemak dengan penurunkan kadar lipoprotein densitas rendah (LDL) dan meningkatkan kadar lipoprotein densitas tinggi (HDL). Hal ini mengakibatkan hambatan pada dinding arteri menjadi berkurang dan kekuatan aliran darah menjadi normal sehingga tekanan darah dapat menurun (Potter \& Perry, 2006).

Salah satu sistem tubuh yang mengontrol tekanan darah adalah baroreseptor yang berarti merasakan nilai tekanan darah. Ketika tekanan darah turun baroreseptor bereaksi dengan meningkatkan denyut jantung dan respon sistem saraf simpatik sehingga pembuluh 
darah berkontraksi dan tekanan darah dipertahankan. Menurut Townsend (2010), hipertensi terjadi karena baroreseptor mengatur ulang nilai dasar ditingkat yang lebih tinggi dan mempertahankan nilai tekanan darah yang lebih tinggi tersebut. Dengan latihan peregangan secara teratur dapat mengatur ulang nilai baroreseptor ke tingkat yang lebih rendah dan lebih sehat. Dari uraian diatas dapat disimpulkan bahwa setiap bagian dari latihan yoga memiliki manfaat yang baik bagi tubuh terutama untuk menurunkan tekanan darah. Yoga memiliki efek fisiologis pada kekuatan otot, peningkatan beberapa posisi tubuh yang dipercaya dapat memengaruhi sistem saraf otonom dan kelenjar endokrin yang mengatur fungsi internal termasuk detak jantung dan produksi hormon.

Secara umum, penelitian ini berdasarkan pada kerangka pikir sebagai berikut :

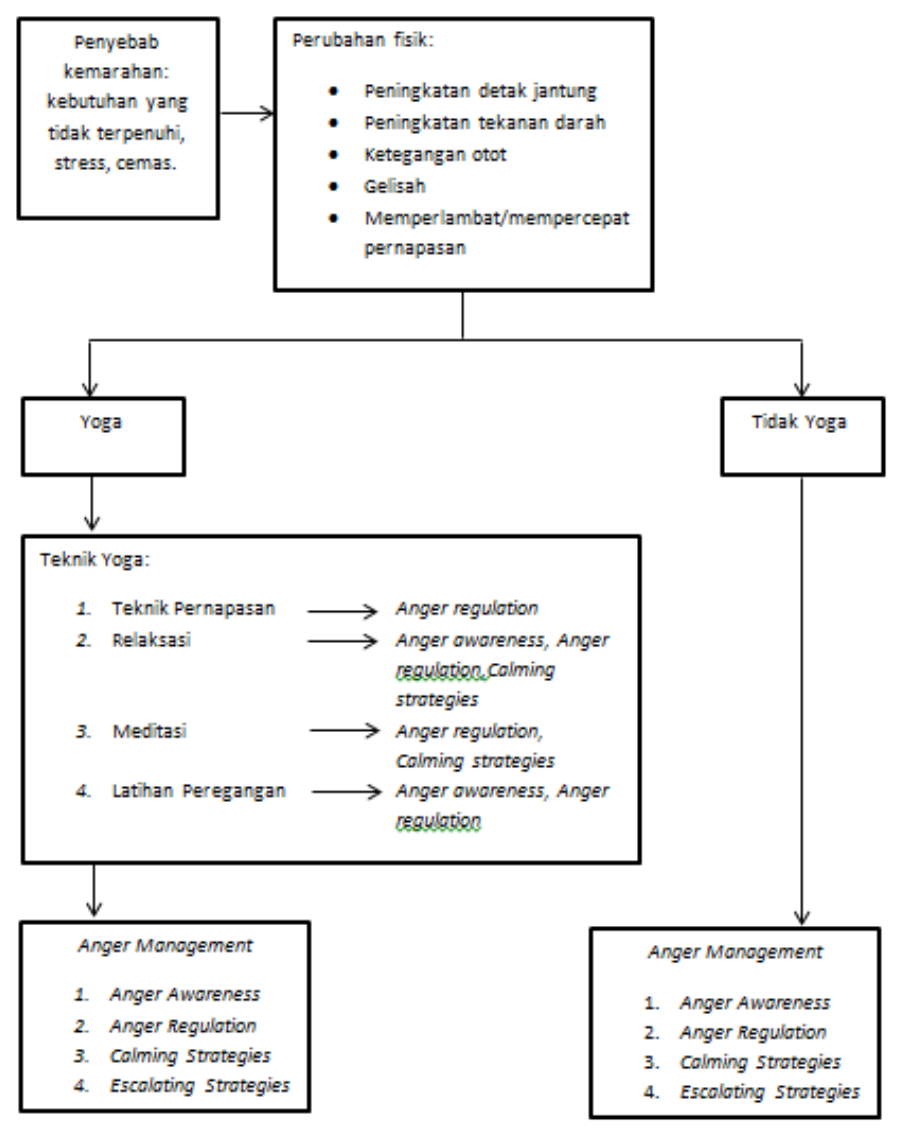

Gambar 1. Kerangka Pikir Penelitian 
Secara spesifik, intervensi yang diberikan berupa penerapan teknik yoga yang terdiri atas 21 postur yang dibagi menjadi dua sesi di mana pada sesi awal terdiri atas 9 pose dan pada sesi menengah terdiri atas 12 pose. Kelompok eksperimen menjalani program pelatihan hatha yoga modifikasi ini selama 4 minggu, dengan frekuensi latihan 2 kali dalam seminggu, dengan durasi waktu 60 menit, dan meditasi selama 20 menit setelah pelatihan.

\section{HASIL PENELITIAN}

Penelitian ini bertujuan untuk mengetahui pengaruh teknik yoga Anger Management pada wanita dewasa awal yang mengikuti yoga. Kelompok eksperimen mengikuti teknik yoga dan kelom- pok kontrol tidak mengikuti yoga. Sampel penelitian berjumlah 120 orang yang terdiri atas 60 responden yang mengikuti yoga dan 60 responden yang tidak mengikuti yoga. Hipotesis statistik yang akan diuji adalah sebagai berikut :

$\mathrm{H}_{0}$ : Tidak terdapat perbedaan anger management wanita dewasa awal yang mengikuti dan tidak mengikuti yoga di Bandung

$\mathrm{H}_{1}$ : Terdapat perbedaan anger management wanita dewasa awal yang mengikuti dan tidak mengikuti yoga di Bandung

Dengan kriteria uji, tolak $\mathrm{H}_{0}$ jika Sig. $<\alpha$ $(0,05)$.

Berdasarkan perhitungan menggunakan SPSS 21. for windows, didapatkan hasil uji Mann-Whitney sebagai berikut:

Tabel 2. Hasil Uji Mann-Whitney Anger Management

\begin{tabular}{cccc}
\hline Variabel & Asymp sign & $\begin{array}{c}\text { Keterangan } \\
\mathbf{\alpha}=\mathbf{0 , 0 5}\end{array}$ & Status \\
\hline Anger Management & 0,000 & Sig. $<\mathbf{\alpha}, \mathrm{H}_{0}$ ditolak & $\mathrm{H}_{0}$ ditolak \\
\hline
\end{tabular}

Berdasarkan hasil pengukuran tidak mengikuti yoga di Bandung. Bila menggunakan uji Mann-Whitney, diketadilihat perbandingannya, maka kedua hui bahwa $\mathrm{H}_{0}$ ditolak. Hal ini berarti kelompok sampel dapat dilihat dalam terdapat perbedaan Anger Management bagan sebagai berikut : wanita dewasa awal yang mengikuti dan 


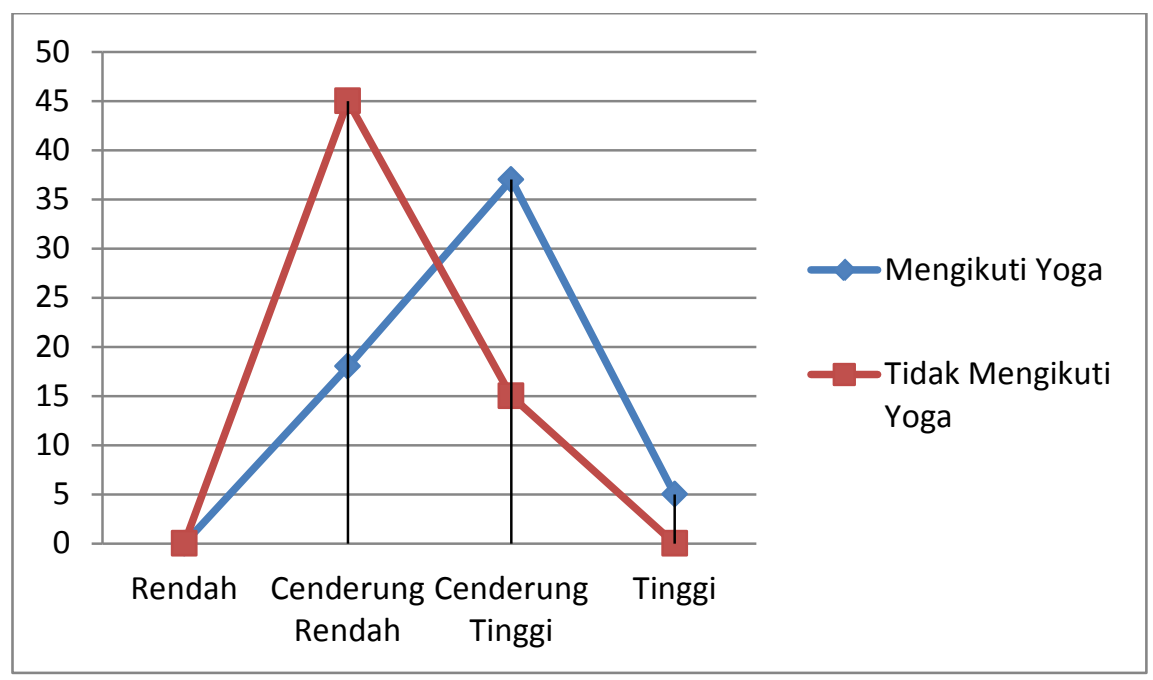

Gambar 2. Perbedaan Anger Management yang mengikuti dan tidak mengikuti yoga

Gambar di atas menunjukkan bahwa kelompok eksperimen yang mengikuti yoga memiliki jumlah responden yang memiliki anger management lebih tinggi dibandingkan dengan kelompok kontrol yang tidak melakukan yoga. Kelompok responden yang melakukan yoga lebih banyak memiliki responden yang termasuk kategori cenderung tinggi dan ada beberapa responden yang termasuk kategori tinggi, sedangkan dalam kelompok yang tidak mengikuti yoga lebih banyak responden yang termasuk kategori cenderung rendah dan tidak ada responden yang termasuk kategori tinggi. Oleh karena itu, dapat dimaknakan bahwa wanita yang mengikuti yoga memiliki kemampuan dalam mengenali emosi marah diri sendiri, mengendalikan emosi marah, meredakan emosi marah, mengenali emosi marah orang lain, dan mampu mengungkapkan amarah secara asertif yang lebih baik dibandingkan kelompok wanita yang tidak mengikuti yoga. Terdapat perbedaan pada kemampuan mengatur pikiran, perasaan, nafsu amarah yang dimiliki oleh wanita yang mengikuti yoga, di mana sebagian besar wanita yang mengikuti yoga masuk dalam kategori cenderung tinggi $(61,67 \%)$. Sedangkan sebagian besar wanita yang tidak mengikuti yoga masuk dalam kategori cenderung rendah $(75 \%)$. Merujuk pada data tersebut, dapat dilihat bahwa kelompok wanita yang mengikuti yoga memiliki kemampuan sedikit lebih baik berdasarkan dimensi pembentuk anger management dibandingkan kelom-pok wanita yang tidak mengikuti yoga. 
Dalam Anger Management terdapat empat dimensi di dalamnya yang terdiri atas anger awareness, anger regulation, calming strategies dan escalating strategies. Untuk melihat lebih jauh bagaimana perbedaan setiap dimensi antara wanita dewasa awal yang mengikuti yoga dan tidak mengikuti yoga, maka peneliti melakukan uji MannWhitney untuk setiap dimensi sebagai berikut:

Tabel 3. Hasil Uji Mann-Whitney Dimensi-dimensi Anger Management

\begin{tabular}{cccc}
\hline Variabel & Asymp sign & Keterangan & Status \\
\hline Anger Awareness & 0,058 & Sig. $<\alpha, \mathrm{H} 0$ diterima & Ho diterima \\
Anger Regulation & 0,000 & Sig. $<\alpha, \mathrm{HO}$ ditolak & Hoditolak \\
Calming Strategies & 0,000 & Sig. $<\alpha, \mathrm{H} 0$ ditolak & $\mathrm{H}_{0}$ ditolak \\
Escalating Strategies & 0,983 & Sig. $<\alpha \mathrm{HO}$ diterima & $\mathrm{H}_{0}$ diterima \\
\hline
\end{tabular}

Berdasarkan hasil pengukuran uji Mann-Whitney terlihat bahwa ada dua dimensi Anger Management $\mathrm{H}_{0}$ ditolak, yaitu dimensi anger regulation dan calming strategies dan dua dimensi Anger Management $\mathrm{H}_{0}$ diterima yaitu anger awareness dan escalating strategies. Hal ini berarti terdapat perbedaan anger regulation dan calming strategies antara wanita yang mengikuti dan tidak mengikuti yoga dan tidak terdapat perbedaan anger awareness dan escalating strategies antara wanita yang mengikuti dan tidak mengikuti yoga.

Dalam kedua kelompok, tidak terdapat perbedaan dari sisi Anger Awareness, yaitu kemampuan untuk mengenali rasa marah dan faktor-faktor penyebabnya. Tidak terdapat pula perbedaan pada Escalating Strategies, atau kemampuan untuk mengenali emosi marah orang lain atau empati dan dapat mengungkapkan emosi marah secara asertif. Namun terdapat perbedaan pada dua dimensi lain yang membentuk anger management individu.

Anger regulation pada wanita yang mengikuti yoga dominan pada kategori cenderung tinggi sebesar 51,6\%. Hal ini berarti responden memiliki kemampuan dalam mengendalikan emosi marahnya dengan cukup baik. Dalam yoga terdapat teknik pernapasan yang membantu individu dalam mengendalikan emosi marah dengan menarik napas dalam-dalam sehingga menjadi tidak panik, membuat 
tubuh dan pikiran menjadi lebih tenang. Selain itu, yoga membuat individu berkonsentrasi untuk dapat berpikir positif. Memikirkan apa yang harus dilakukan saat terjadinya kemarahan sehingga terhindar dari kemarahan yang dapat merugikan diri sendiri dan orang lain. Dalam mengendalikan kemarahan, relaksasi di dalam yoga berperan dalam mengembalikan tubuh agar stabil kembali. Relaksasi membuat individu tenang karena oksigen yang berada dalam tubuh seimbang sehingga memperlancar peredaran darah.

Calming strategies juga berbeda pada kedua kelompok. Kelompok wanita yang mengikuti yoga termasuk pada kategori cenderung tinggi sebesar $45 \%$. Hal ini berarti kemampuan yang cukup baik dalam menenangkan diri sendiri setelah individu marah. Individu akan mengalami kesulitan untuk meredakan amarahnya, jika pikirannya masih dipenuhi oleh kemarahan. Pemikiran tentang rasa marah sekecil apapun dapat mencetuskan kembali perasaan marah yang lebih besar. Untuk menghentikan pikiran saat marah, dapat ditempuh dengan cara mengalihkan perhatian dari apa yang memicu amarah tersebut. Wanita yang mengikuti yoga memiliki berbagai cara untuk mengalihkan kemarahannya sehingga tidak sampai kema- rahan tersebut terlihat baik secara verbal maupun non-verbal dan merugikan diri sendiri atau orang lain. Cara yang dilakukan untuk meredakan kemarahannya seperti pergi menyendiri, pergi ke tempat yang menyenangkan atau menenangkan, beribadah, pergi berolahraga, pergi untuk berlatih yoga, atau melakukan relaksasi lain agar menjadi lebih tenang.

Berdasarkan penelitian ini, dapat disimpulkan bahwa yoga memiliki peran yang baik sebagai intervensi dalam melakukan anger management pada wanita dewasa awal. Kemampuan yoga dalam membuat relaksasi tubuh dan menenangkan pikiran memberikan efek baik secara fisik maupun psikis yang berguna dalam mengelola emosi marah yang terdapat pada diri individu.

\section{SIMPULAN DAN SARAN}

\section{Simpulan}

Berdasarkan hasil pengolahan data menggunakan uji mann-whitney yang dilakukan terhadap skor anger management dengan kedua kelompok responden penelitian, didapatkan hasil bahwa terdapat perbedaan skor anger management antara wanita yang mengikuti yoga dan wanita yang tidak mengikuti yoga. Hasil tersebut menunjukkan adanya perbedaan 
kemampuan mengatur pikiran, perasaan, nafsu amarah yang dimiliki oleh wanita yang mengikuti yoga, di mana sebagian besar wanita yang mengikuti yoga masuk dalam kategori cenderung tinggi. Sedangkan sebagian besar wanita yang tidak mengikuti yoga masuk dalam kategori cenderung rendah. Merujuk pada data tersebut, dapat dilihat bahwa kelompok wanita yang mengikuti yoga memiliki kemampuan sedikit lebih baik berdasarkan dimensi pembentuk anger management dibandingkan kelompok wanita yang tidak mengikuti yoga.

Perbedaan anger management, signifikan berbeda pada dimensi anger regulation, calming strategies. Wanita yang mengikuti yoga dapat lebih mampu mengendalikan emosi marahnya, mampu meredakan emosi marahnya, dibandingkan wanita yang tidak mengikuti yoga. Namun tidak terdapat perbedaan yang signifikan pada dimensi anger awareness, escalating strategies. Kemampuan dalam mengenali rasa marah dan faktor-faktor penyebab serta kemampuan untuk mengenali emosi marah orang lain tidak ada perbedaan.

\section{Saran}

Penelitian ini memiliki fokus melakukan intervensi menggunakan teknik yoga. Teknik lain dapat diujicobakan untuk mendapatkan efek relaksasi guna memberikan dampak pada faktor-faktor pembentuk anger management pada wanita dewasa awal.

\section{DAFTAR PUSTAKA}

Allred, K. G., Mallozzi, J. S., Matsui, F., $\&$ Raia, C. P. (1997). The influence of anger and compassion on negotiation performance. Organizational Behavior and Human Decision Processes, 70, 175-187.

Bhave, S.Y. \& Saini, S. (2009). Anger management. India: SAGE Publications India Pvt Ltd.

Denson, T.F. \& Fabiansson, E.C. (2010). The effects of anger and anger regulation on negotiation. Sydney, NSW 2052, Australia: University of New South Wales.

Deffenbacher, J.L. (2009). Angry drivers: Characteristics and clinical interventions. Revista Mexicana de Psicología, 26 (1), 5-16.

Goleman, D. (1997). Working with emotional intelligence. US: Bantam Books

Goleman, D. (2002). Emotional intelligence. Jakarta: PT Gramedia Pustaka Utama 
Hershorn, M. (2005). 60 second anger management. Jakarta : PT. Bhuana Ilmu Populer

http://www.apa.org/helpcenter/controllin g-anger.aspx

Jain, R. (2011). Pengobatan alternatif untuk mengatasi tekanan darah. Jakarta: Gramedia Pustaka Utama

Kelliat, B.A. (1993). Marah akibat perilaku yang diderita. Jakarta: EGC.

Nazir, M. (2005). Metode penelitian. Bogor: Ghalia Indonesia.

Potegal, M., Stemmler, G., \& Spielberger, C. (2010). International handbook of anger. USA: Springer

Potter T. \& Perry, S. (1997). Buku ajar fundamental keperawatan: Konsep, proses, dan praktik. Edisi4 Vol 2. Jakarta: EGC.

Rawls, E.S. (2010). Yoga for modern living. Horwitz Publication
Santrock, J. W. (1999). Life span development. Boston: McGrawHill

Santrock, J. W. (2002). Life span development. Boston: McGrawHill

Shindu, P. (2013). Panduan lengkap Yoga: Untuk hidup sehat dan seimbang. Bandung: PT Mizan Pustaka

Stuart, G.W. \& Sundeen, S.J. (1998). Buku saku keperawatan jiwa (Terjemahan). Jakarta: EGC.

Tice, D. M., \& Baumeister, R. F. 1993. Controlling anger: Self-induced emotion change. In D. M. Wegner \& J. W. Pennebaker (Eds.), Handbook of mental control (pp. 393-409). Upper Saddle River, NJ: Prentice-Hall, Inc

Townsend, R.R. (2010). 100 tanya jawab mengenai tekanan darah tinggi (hipertensi). Jakarta: Indeks

Videbeck, S.L. (2008). Buku ajar keperawatan jiwa. Jakarta: EGC. 